Research Paper

\title{
Inorganic Polyphosphates Regulate Hexokinase Activity and Reactive Oxygen Species Generation in Mito- chondria of Rhipicephalus (Boophilus) microplus Embryo
}

Amanda Fraga ${ }^{1}$, Jorge Moraes ${ }^{1,2}$, José Roberto da Silva ${ }^{1,2}$, Evenilton P. Costa ${ }^{3}$, Jackson Menezes ${ }^{1,2}$, Itabajara da Silva Vaz Jr2,4, Carlos Logullo ${ }^{2,3}$, Rodrigo Nunes da Fonseca ${ }^{1,2}$ and Eldo Campos ${ }^{1,2}$

1. Laboratório Integrado de Bioquímica - Hatisaburo Masuda, UFRJ, Polo Barreto, Av. São José do Barreto nº 764, São Jose do Barreto, CEP 27971-550, Macaé, RJ, Brazil;

2. Instituto Nacional de Ciência e Tecnologia - Entomologia Molecular, Rio de Janeiro, RJ, CEP 21941-590, Brazil;

3. Laboratório de Química e Função de Proteínas e Peptídeos and Unidade de Experimentação Animal-CBB-UENF, Avenida Alberto Lamego, 2000, Horto, Campos dos Goytacazes, RJ, CEP 28015-620, Brazil;

4. Centro de Biotecnologia e Faculdade de Veterinária, UFRGS, Avenida Bento Gonçalves, 9090, Porto Alegre, RS, C.P. 15005, CEP 91501-970, Brazil.

$\triangle$ Corresponding author: Tel.: +55-22-33993967. E-Mail address: eldocampos@macae.ufrj.br (E. Campos).

() Ivyspring International Publisher. This is an open-access article distributed under the terms of the Creative Commons License (http://creativecommons.org/ licenses/by-nc-nd/3.0/). Reproduction is permitted for personal, noncommercial use, provided that the article is in whole, unmodified, and properly cited.

Received: 2013.05.06; Accepted: 2013.08.08; Published: 2013.08.27

\begin{abstract}
The physiological roles of polyphosphates (poly P) recently found in arthropod mitochondria remain obscure. Here, the possible involvement of poly $P$ with reactive oxygen species generation in mitochondria of Rhipicephalus microplus embryos was investigated. Mitochondrial hexokinase and scavenger antioxidant enzymes, such as superoxide dismutase, catalase, and glutathione reductase were assayed during embryogenesis of $R$. microplus. The influence of poly $\mathrm{P}_{3}$ and poly $\mathrm{P}_{15}$ were analyzed during the period of higher enzymatic activity during embryogenesis. Both poly Ps inhibited hexokinase activity by up to $90 \%$ and, interestingly, the mitochondrial membrane exopolyphosphatase activity was stimulated by the hexokinase reaction product, glucose-6-phosphate. Poly $\mathrm{P}$ increased hydrogen peroxide generation in mitochondria in a situation where mitochondrial hexokinase is also active. The superoxide dismutase, catalase and glutathione reductase activities were higher during embryo cellularization, at the end of embryogenesis and during embryo segmentation, respectively. All of the enzymes were stimulated by poly $P_{3}$. However, superoxide dismutase was not affected by poly $\mathrm{P}_{15}$, catalase activity was stimulated only at high concentrations and glutathione reductase was the only enzyme that was stimulated in the same way by both poly Ps. Altogether, our results indicate that inorganic polyphosphate and mitochondrial membrane exopolyphosphatase regulation can be correlated with the generation of reactive oxygen species in the mitochondria of $R$. microplus embryos.
\end{abstract}

Key words: inorganic polyphosphate; reactive oxygen species; arthropod; mitochondria; scavenger antioxidant enzymes.

\section{Introduction}

Inorganic polyphosphates (poly $\mathrm{P}$ ) are long chains of a few to several hundred phosphate residues linked by phosphoanhydride bonds. Polyphosphates have been found in all cell types examined to date and have been demonstrated to play diverse roles depending on the cell type and circumstances $[1,2]$. The biological roles played by polyphosphates have been most extensively studied in prokaryotes and unicel- 
lular eukaryotes, where they have been shown to regulate many biochemical processes including the metabolism and transport of inorganic phosphate, cation sequestration and storage [1], membrane channel formation $[3,4]$, cell envelope formation and bacterial pathogenesis[5,6], regulation of gene and enzyme activities [7] and activation of Lon proteases [8].

Conversely, poly P functions have not been extensively investigated in higher eukaryotes, although some functions have been described such as the activation of TOR kinase [9], involvement in blood coagulation [10], and apoptosis [11-13]. Regarding mitochondrial metabolism, mammalian mitochondrial poly $\mathrm{P}$ production is directly linked to their energetic state [14], as the level of poly $P$ regulates the level of cellular ATP [14] and $\mathrm{Ca}^{2+}$ accumulation [15]. The interest in mitochondrial poly $\mathrm{P}$ is focused on two aspects: poly $\mathrm{P}$ as a macroenergetic compound with the same energy of hydrolysis of the phosphoanhydride bond as ATP, and the fact that, according to the endosymbiotic theory, mitochondria originated from ancient prokaryotic cells; thus, it would be intriguing to discover whether or not mitochondria have preserved polyphosphate functions such as the regulation of energy metabolism [16, 17]. Recently, we have demonstrated that electron flux and redox states may exert some influence and be influenced by the activity of membrane exopolyphosphatase (PPX), the enzyme that splits $\mathrm{P}_{\mathrm{i}}$ off the end of a poly $\mathrm{P}$ chain, suggesting that it plays a role in energy supply during $R$. $m i-$ croplus embryogenesis [18].

The metabolism of free hexoses begins by phosphorylation in a reaction catalyzed by the hexokinase (ATP: hexose-6-phosphotransferase, E.C. 2.7.1.1; HK). This enzyme has been characterized in several organisms [19-24]. Four distinct hexokinase isozymes are reported for mammalian tissues and are named types I-IV. These isozymes have an internal repeat sequence in their $\mathrm{N}$ - and $\mathrm{C}$ - terminal halves that is found in mammals, insects and nematodes [20, $25,26]$. In arthropods the binding mechanism of HK to the outer mitochondrial membrane is not fully established.

The mitochondrial electron transport system (ETS) represents one of the major sources of cellular reactive oxygen species (ROS) such as superoxide $(\mathrm{O} 2 \bullet-)$ and hydrogen peroxide $\left(\mathrm{H}_{2} \mathrm{O}_{2}\right)$, providing continuous generation of these toxic products [27]. The scavenger activity of antioxidant enzymes constitutes an essential mechanism directed against the primary ROS generated by mitochondrial ETS. Superoxide dismutase (SOD) rapidly converts $\mathrm{O}_{2}{ }^{\circ}-$ to $\mathrm{H}_{2} \mathrm{O}_{2}$, protecting the mitochondrial iron-sulfur cluster-containing enzymes from $\mathrm{O}_{2}{ }^{\circ}-$ attack [28]. This enzyme is present in the matrix (Mn-SOD) and in the intermembrane space (Zn-SOD) [29-32]. The abundance of this enzyme, as well as its presence in both mitochondrial compartments, attests to the importance of removing mitochondrially-generated $\mathrm{O}_{2}{ }^{-}-$[33]. Catalase (CAT) acts by decomposing $\mathrm{H}_{2} \mathrm{O}_{2}$ into $\mathrm{H}_{2} \mathrm{O}$ and $\mathrm{O}_{2}$, avoiding the production of hydroxyl radicals $\left(\mathrm{HO}^{*}\right)$ in the presence of transition metals. The presence of CAT in mitochondria is of great importance, as decomposition of $\mathrm{H}_{2} \mathrm{O}_{2}$ protects these organelles against intra- and extra-mitochondrially generated $\mathrm{H}_{2} \mathrm{O}_{2}$ [34, 35]. Glutathione reductase (GR) is the enzyme that regenerates reduced glutathione in the mitochondrial matrix. Reduced glutathione can scavenge ROS non-enzymatically or by serving as an electron-donating substrate to several enzymes involved in ROS-detoxification [36].

Ticks are vectors of parasites that cause hemoparasitic diseases and are endemic in many cattle production areas [37]. The present study focuses on Rhipicephalus microplus, which causes heavy economic losses to bovine herds, particularly in tropical regions; thus, major efforts have been directed toward developing immunoprophylactic tick-control tools [38, 39]. R. microplus has only one host throughout its three life stages, which is usually a bovine, and has a long feeding period (approximately 21 days). Female ticks, after engorgement, drop off the host and initiate oviposition approximately three days later. Being an oviparous animal, embryogenesis occurs in the absence of exogenous nutrients; maternal nutrients are packaged into oocytes and stored mostly as yolk granules. Hatching occurs approximately 21 days after egg laying and the emerging larvae can survive for several weeks before finding a host, using the remaining yolk as their only energy source $[40,41]$.

The aim of this study was to investigate the possible involvement of poly $\mathrm{P}$ in reactive oxygen species generation in mitochondria of $R$. microplus embryos. Such findings could reveal an important role for poly P metabolism in arthropods.

\section{Materials and Methods}

\section{Ticks and reagents}

Ticks were obtained from a colony maintained at the Faculdade de Veterinária, Universidade Federal do Rio Grande do Sul (UFRGS), Brazil as previously described [39]. R. microplus (Acarina, Ixodidae) ticks from the Porto Alegre strain, free of parasites, were reared on calves obtained from a tick-free area. Engorged adult females were maintained in Petri dishes at $28^{\circ} \mathrm{C}$ and $80 \%$ relative humidity upon completion of oviposition, which starts approximately three days after adult ticks drop off calves. Animals were treated 
in compliance with the UFRGS review committee for animal care. The reagents were purchased from Sigma (USA), Amersham Biosciences (USA), Invitrogen (USA) and Merck (Germany).

\section{Isolation of Mitochondria}

The cell fractionation procedure used required large amounts of fresh eggs (at least $2 \mathrm{~g}$ ) to obtain functionally active mitochondrial fractions. Mitochondria were isolated by differential centrifugation, following the procedure described by [42]. Eggs were homogenized in a buffer containing $0.5 \mathrm{M}$ sucrose, 100 $\mu \mathrm{M}$ leupeptin, $100 \mathrm{nM}$ pepstatin, $1 \mathrm{mM}$ PMSF, $10 \mathrm{mM}$ EGTA, 1\% bovine albumin (fat acid free) and $50 \mathrm{mM}$ HEPES, pH 7.4. The homogenate was centrifuged at $500 \mathrm{X} \mathrm{g}$ for $5 \mathrm{~min}$. The supernatant was carefully removed and centrifuged at 2,000 X g for $10 \mathrm{~min}$ to yield a nuclear pellet. Then, the supernatant was submitted to another centrifugation at 7,000 X g for $15 \mathrm{~min}$ and the mitochondrial pellet that resulted was re-suspended in a storage buffer containing $120 \mathrm{mM}$ $\mathrm{KCl}, 1 \mathrm{mM}$ EGTA, $0.2 \%$ bovine albumin, and $10 \mathrm{mM}$ Tris $\mathrm{HCl}, \mathrm{pH}$ 7.4. Isolation of the mitochondrial membrane fraction was performed by sonication of freshly prepared mitochondria three times for $20 \mathrm{~s}$ at the maximal output using an MSE ultrasonic disintegrator. The suspension was centrifuged for $10 \mathrm{~min}$ at $12,000 \times g$ to remove unbroken mitochondria. The supernatant was centrifuged at $100,000 \times g$ for $60 \mathrm{~min}$ to yield the mitochondrial membrane fraction and the pellet was re-suspended in a buffer containing $10 \mathrm{mM}$ Tris $\mathrm{HCl}, \mathrm{pH} 7.4[18]$. Protein was determined by the Folin-Lowry method using bovine serum albumin as a standard [43].

\section{Determination of mitochondrial hexokinase activity}

The activity of mitochondrial hexokinase was determined based on [27]. A $0.1 \mathrm{mg} / \mathrm{mL}$ dilution of mitochondrial protein was used and mitochondrial hexokinase was determined by NADH formation; the absorbance was followed at $340 \mathrm{~nm}$ at $37^{\circ} \mathrm{C}$ using a molar extinction coefficient of $6.22 \mathrm{M}^{-1}$. The assay medium contained $10 \mathrm{mM}$ Tris $\mathrm{HCl}, \mathrm{pH} 7.4,5 \mathrm{mM}$ glucose, $10 \mathrm{mM} \mathrm{MgCl}$, $1 \mathrm{mM} \beta$-NAD ${ }^{+}, 2$ units $/ \mathrm{ml}$ G6PDH (glucose-6-phosphate dehydrogenase) from Leuconostoc mesenteroides and $50 \mathrm{mM}$ Ap5A (P1,P5-di(adenosine 50)-pentaphosphate), in a final volume of $1 \mathrm{~mL}$. The reaction was started by adding 1 mM ATP.

\section{Exopolyphosphatase Assay}

The reaction mixture consisted of $50 \mathrm{mM}$ Tris $\mathrm{HCl}$ buffer ( $\mathrm{pH} 7.4$ ) and $5 \mathrm{mM} \mathrm{MgCl}$, using $5 \mathrm{mM}$ polyP $\mathrm{P}_{3}$ as the substrate. Reactions were performed at $37^{\circ} \mathrm{C}$. The $\mathrm{P}_{\mathrm{i}}$ formed during the reaction was spectrophotometrically determined as described by[44], adding a solution of $0.5 \%$ ammonium molybdate, 0.35 $\mathrm{M}$ sulfuric acid, $0.5 \%$ sodium dodecyl sulfate, and $10 \%$ ascorbic acid. Measurements of absorbance at 750 $\mathrm{nm}$ were performed after $15 \mathrm{~min}$. One unit of enzyme activity (U) was defined as the quantity of enzyme liberating $1 \mu \mathrm{moL}$ of Pi per min. PPX activity during mitochondrial respiration was measured using a reaction mixture consisting of $50 \mathrm{mM}$ Tris $\mathrm{HCl}$ buffer (pH 7.4), $120 \mathrm{mM} \mathrm{KCl}, 1 \mathrm{mM}$ EGTA, $5 \mathrm{mM} \mathrm{MgCl}_{2}$, and $0.2 \mathrm{mM}$ adenosine diphosphate (ADP) in the absence of any Pi source. PolyP $\mathrm{P}_{3}(0.5 \mu \mathrm{M})$ was used as a substrate for PPX activity and $5 \mathrm{mM}$ pyruvate was used as an oxidative substrate. Potassium cyanide (KCN, 1 $\mathrm{mM}$ ) and $20 \mu \mathrm{g} / \mathrm{mL}$ heparin were used to inhibit cytochrome oxidase and PPX activities, respectively. The reaction was performed at $28^{\circ} \mathrm{C}$ for $15 \mathrm{~min}$ [42].

\section{Spectrofluorometric measurements of mito- chondrial $\mathrm{H}_{2} \mathrm{O}_{2}$ generation}

Mitochondrial release of $\mathrm{H}_{2} \mathrm{O}_{2}$ was assessed by the Amplex Red oxidation method [45]. Mitochondria $(0.2 \mathrm{mg}$ protein/ $\mathrm{mL})$ were incubated in buffer containing $10 \mathrm{mM}$ Tris $\mathrm{HCl}, \mathrm{pH} 7.4,0.32 \mathrm{M}$ mannitol, 8 $\mathrm{mM}$ inorganic phosphate, $5 \mathrm{mM} \mathrm{MgCl}_{2}, 0.08 \mathrm{mM}$ EDTA, $1 \mathrm{mM}$ EGTA, $1 \mathrm{mM}$ ATP, $10 \mathrm{mM}$ succinate and $0.2 \mathrm{mg} / \mathrm{mL}$ fatty acid-free bovine serum albumin supplemented with $10 \mathrm{mM}$ Amplex Red and 2 units/mL horseradish peroxidase. After $5 \mathrm{~min}$ incubation, the fluorescence (Ex: 563nm; Em: 587nm) was measured using a Cary Eclipse spectrofluorometer. The total $\mathrm{H}_{2} \mathrm{O}_{2}$ released was corrected for non-specific oxidation of Amplex Red measured in the absence of horseradish peroxidase. The maximal rate $(100 \%)$ of mitochondrial $\mathrm{H}_{2} \mathrm{O}_{2}$ formation was assumed to be the difference between the rate of $\mathrm{H}_{2} \mathrm{O}_{2}$ formation in the absence of oxidative substrate and that measured after the addition of succinate.

\section{Determination of Mn-SOD activity}

The mitochondrial fraction $(20 \mu \mathrm{g} / \mathrm{mL})$ was used to determine Mn-SOD activity using an indirect competition assay between SOD and an indicator molecule, nitroblue tetrazolium [46]. The reaction mixture contained $13 \mathrm{mM}$ methionine, $75 \mu \mathrm{M}$ nitroblue tetrazolium, $100 \mathrm{mM}$ ethylenediamine tetraacetic acid (EDTA), and $2 \mu \mathrm{M}$ riboflavin in phosphate buffer ( $50 \mathrm{mM}, \mathrm{pH} 7.4$ ) to a final volume of $1 \mathrm{~mL}$ at $25^{\circ} \mathrm{C}$; the change in absorbance was observed at $560 \mathrm{~nm}$. One unit of SOD was defined as the amount of enzyme needed to inhibit the reduction of nitroblue tetrazolium (NBT) by $50 \%$. Sodium cyanide $(5 \mathrm{mM})$ was used to inhibit $\mathrm{Cu} / \mathrm{ZnSOD}$ activity. 


\section{Determination of CAT activity}

CAT activity was determined according to the method of Aebi[47]. The mitochondrial fraction (50 $\mathrm{mg} / \mathrm{mL}$ ) was added to phosphate buffer $(50 \mathrm{mM}, \mathrm{pH}$ 7.0) containing $15 \mathrm{mM} \mathrm{H}_{2} \mathrm{O}_{2}$ as substrate; the change in absorbance was noted at $240 \mathrm{~nm}$ at $25^{\circ} \mathrm{C}$ using an extinction coefficient of $43.6 \mathrm{M}^{-1} \mathrm{~cm}^{-1}$. The specificity of CAT activity to degrade $\mathrm{H}_{2} \mathrm{O}_{2}$ was confirmed by inhibiting the activity with aminotriazole $(20 \mathrm{mM})$, a compound that is a specific catalase inhibitor [48].

\section{Determination of $\mathbf{G R}$ activity}

GR activity was measured by monitoring the oxidation of $\beta$-NADPH [49]. The reaction mixture contained $1 \mathrm{mM}$ GSSG and $0.1 \mathrm{mM} \beta$-NADPH in phosphate buffer (0.1 M, pH 7.0) in a final volume of 1 $\mathrm{mL}$ at $30^{\circ} \mathrm{C}$. The reaction was initiated by adding the mitochondrial fraction $(50 \mathrm{mg} / \mathrm{mL})$ to the cuvette and following the decrease in absorbance at $340 \mathrm{~nm}$ at $30^{\circ} \mathrm{C}$. One unit of GR was equivalent to the oxidation of $1 \mathrm{mmol}$ of NADPH per min at $\mathrm{pH} 7.0$ at $30^{\circ} \mathrm{C}$.

\section{Statistical analysis}

Results were expressed as mean \pm standard error $( \pm \mathrm{SE})$ and one-way ANOVA was used for statistical analysis, followed by the post hoc Tukey test. Data were considered statistically significant when $\mathrm{P}<$ 0.05 .

\section{Results and Discussion}

Although the first evidence for the presence of poly $\mathrm{P}$ in mammalian cells was obtained a long time ago [50], relatively few studies have addressed its physiological roles in animal cells $[1,9-12,14,18,42$, 51, 52].

Early R. microplus embryonic stages are similar to those of mosquitoes [53]. Tick embryogenesis is characterized by the formation of a cellularized blastodermal cell layer up to day 4 . Thereafter, the embryo starts segment formation and initiates organogenesis $[24,54]$. Previously, we provided evidence that mitochondrial membrane PPX plays a role in energy metabolism in $R$. microplus during embryo development [18]. Here, we demonstrate that inorganic polyphosphate and mitochondrial membrane PPX regulation can be correlated to the generation of reactive oxygen species in mitochondria during $R$. microplus embryo development.

\section{Regulation of mitochondrial hexokinase by inorganic polyphosphate}

Mitochondria from tick embryos were previously characterized by our research group [18, 42, 51]. Mitochondria from tick embryos were isolated and the mitochondrial hexokinase activity was analyzed during $R$. microplus embryogenesis. The activity was higher $(320.7 \pm 50)$ during embryo cellularization, on the $3^{\text {rd }}$ day of development (Figure 1A). The profile was not altered after normalization for mitochondrial recovery using the specific activity of $\mathrm{F}_{1} \mathrm{~F}_{\mathrm{o}}$ APTase as a specific mitochondrial marker instead of mitochondrial protein (data not shown). Cytoplasmic hexokinase activity during R. microplus embryogenesis has already been determined by da-Silva [55], and showed a distinct profile. Our results suggest that a mitochondrial hexokinase isoform exists, because higher levels of activity were observed in mitochondria during early embryogenesis, while higher levels were observed in the cytoplasm near larval eclosion [55] indicating different roles for these isoforms during embryo development. The day corresponding to the peak of activity (day 3) was used to analyze the influence of poly $\mathrm{P}_{3}$ and poly $\mathrm{P}_{15}$ on mitochondrial hexokinase. Both poly Ps inhibited mitochondrial hexokinase activity by up to $90 \%$ at a $20 \mu \mathrm{M}$ concentration (Figure $1 \mathrm{~B}$ and $1 \mathrm{C}$ ).

To confirm the relationship between mitochondrial hexokinase and poly P metabolism, the effects of glucose-6-phosphate, a hexokinase reaction product, on mitochondrial membrane PPX activity was evaluated. In fact, mitochondrial membrane PPX activity was stimulated by about $40 \%$ when using $2 \mathrm{mM}$ glucose-6-phosphate (Figure 2). The observed decrease in mitochondrial hexokinase activity by poly $\mathrm{P}$ and the increase in mitochondrial membrane PPX activity by glucose-6-phosphate indicate a co-regulation between these enzymes.

A portion of basal mitochondrial respiration results from the consumption of oxygen that is promoted by ADP recycling by mitochondrial kinases [56]. We have previously demonstrated that poly $\mathrm{P}$ can be used as a $P_{i}$ donor for adenosine-5'-triphosphate (ATP) synthesis in ticks [42]. To obtain further insight into the relationship between these enzymes during mitochondrial respiration, mitochondrial membrane PPX activity was measured using pyruvate as the substrate and poly $\mathrm{P}_{3}$ as the only source of $P_{i}$. Poly $P_{3}$ was used in this assay because the affinity of mitochondrial membrane PPX for polyP $_{3}$ is 10 times stronger than for poly $\mathrm{P}_{15}$ [18]. During this assay, the addition of small amounts of ADP $(0.2 \mathrm{mM})$ induces state 3 followed by state 4 , when all of the ADP was converted to ATP. Thus, during state 3 , a balance exists between $P_{i}$ released by PPX and ATP synthesis, because PPX is measured by the amount of $P_{i}$. Membrane PPX activity increased by a factor of three during mitochondrial respiration when pyruvate and ADP were added, and increased significantly when glucose-6-phosphate was added. Heparin, a PPX inhibitor, and KCN, a mitochondrial elec- 
tron transport inhibitor, were used as controls. Heparin completely inhibited the membrane PPX activity and the stimulatory effects disappeared after mitochondrial respiration inhibition by $\mathrm{KCN}$ (Figure 3 ).

(A)

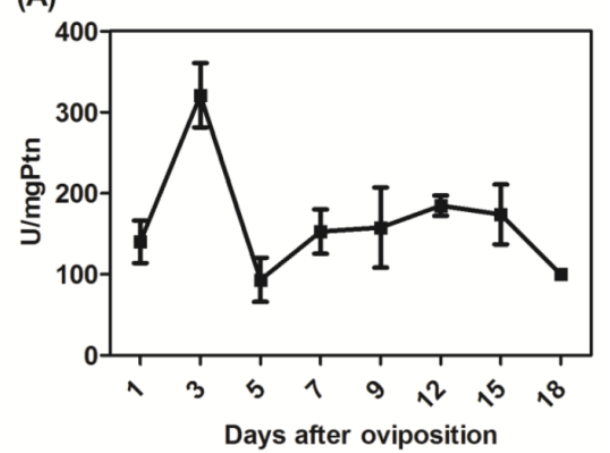

(B)

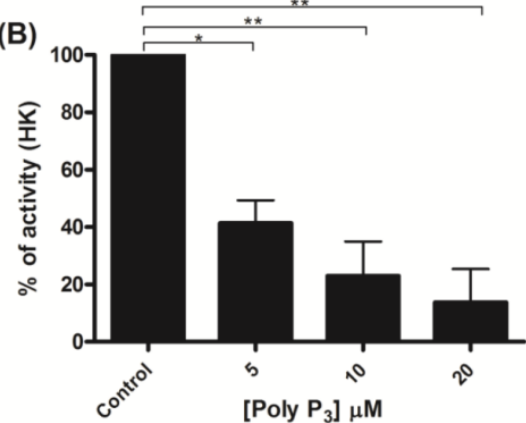

This increase did not occur without ADP addition, indicating that PPX is stimulated during state 3 and the velocity of $P_{i}$ release is higher than the rate of ATP synthesis [18].

Days after oviposition

Fig I. Activity profile of mitochondrial hexokinase and regulation by polyphosphate. (A) Specific HK activity was measured in mitochondria on different days after oviposition and is represented as units per milligram of mitochondrial protein. The HK activity was normalized for mitochondrial recovery using the specific activity of $F_{1} F_{\circ}$ ATPase as a mitochondrial marker, instead of mitochondrial protein, and the same activity profile was obtained (data not shown). (B) Mitochondria were isolated from eggs on the $3^{\text {rd }}$ day of embryogenesis and HK activity was determined in the presence of 5 , 10 and $20 \mu \mathrm{M}$ poly $\mathrm{P}_{3}$. (C) Mitochondria were isolated from eggs on the $3^{\text {rd }}$ day of embryogenesis and HK activity was determined in the presence of 5,10 and $20 \mu \mathrm{M}$ of poly $P_{15}$. Data are the mean \pm S.E. of three independent experiments, in triplicate. ${ }^{*} p<0.05$; ${ }^{* *} p<0.001$.

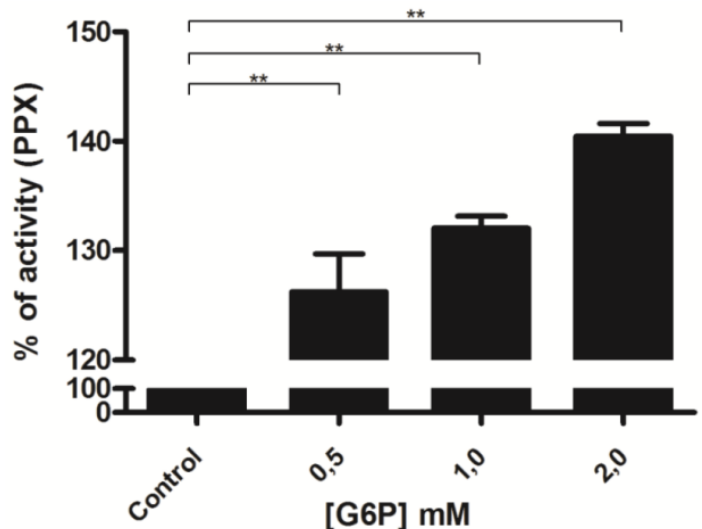

Fig 2. Regulation of membrane mitochondrial PPX by glucose-6-phosphate. Membrane mitochondrial PPX activity was measured in mitochondria from eggs on the $9^{\text {th }}$ day of development using poly $\mathrm{P}_{3}$ as a substrate in the presence of $0.5,1.0$ and $2.0 \mathrm{mM}$ glucose-6-phosphate. Data are the mean $\pm S$.E. of three independent experiments, in triplicate. $* * p<0.001$. 


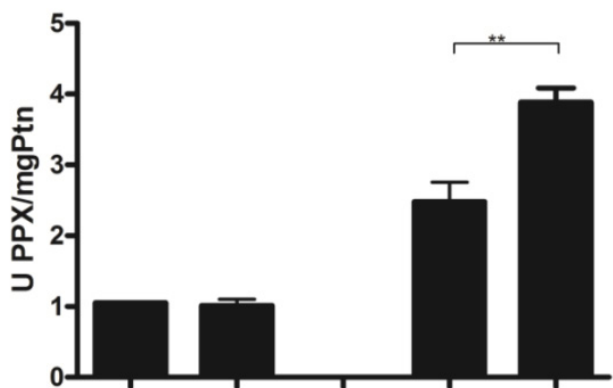

$\begin{array}{llllll}\text { Pyruvate } & - & + & + & + & + \\ \text { ADP } & - & + & + & + & + \\ \text { KCN } & - & + & - & - & - \\ \text { Heparin } & - & - & + & - & - \\ \text { G6P } & - & - & - & - & +\end{array}$

Fig 3. Regulation of mitochondrial PPX activity during mitochondrial respiration. PPX activity was measured in egg mitochondria on the $9^{\text {th }}$ day of development during mitochondrial respiration, using pyruvate as the oxidative substrate, poly $\mathrm{P}_{3}$ as the PPX substrate, $\mathrm{KCN}$ as an inhibitor of the respiratory chain, and Heparin as a PPX inhibitor. The specific activity is represented as units per milligram of mitochondrial protein. Data are the mean \pm S.E. of three independent experiments, in triplicate. ${ }^{* *} \mathrm{p}<0.01$.

The rate of mitochondrial ROS production is highly dependent on mitochondrial membrane potential and inversely related to the availability of ADP used to drive ATP synthesis $[57,58]$. In this context, it was demonstrated that mitochondrial kinases such as hexokinase play a key preventive antioxidant role, avoiding mitochondrial ROS generation[56, 59]. Thus, ADP-producing enzymes would maintain lower mitochondrial membrane potentials and ROS levels in mitochondria [27]. We further confirmed the hypothesis that poly $\mathrm{P}$ is correlated with reactive oxygen species generation in mitochondria by investigating whether poly $\mathrm{P}$ affects $\mathrm{H}_{2} \mathrm{O}_{2}$ generation in a situation where mitochondrial hexokinase also is active. First, it was observed that the addition of 2-deoxyglucose (2-DOG) decreased $\mathrm{H}_{2} \mathrm{O}_{2}$ generation by activating mitochondrial hexokinase. Then the addition of poly $\mathrm{P}_{3}$ and poly $\mathrm{P}_{15}$ restored the $\mathrm{H}_{2} \mathrm{O}_{2}$ levels nearly to control levels by inhibiting mitochondrial hexokinase. When PPX and mitochondrial hexokinase were stimulated at the same time, the $\mathrm{H}_{2} \mathrm{O}_{2}$ generation was lower using poly $\mathrm{P}_{3}$; on the other hand, no significant effect was observed with poly $\mathrm{P}_{15}$ (Figure 4). Our group recently demonstrated that membrane mitochondrial PPX has a $\mathrm{Km}$ of $0.2 \mu \mathrm{M}$ and Vmax of 2.4 $\mu \mathrm{mol} / \mathrm{mg}$ protein.min for poly $\mathrm{P}_{3}$, and a $\mathrm{Km}$ of $2.2 \mu \mathrm{M}$ and Vmax of $1.1 \mu \mathrm{mol} / \mathrm{mg}$ protein.min for poly $\mathrm{P}_{15}$ [18]. These kinetics parameters clarify the reason why, during the time of incubation (5 min) when PPX was stimulated by G6P, the effect on $\mathrm{H}_{2} \mathrm{O}_{2}$ generation was only observed using poly $\mathrm{P}_{3}$ as a substrate. These re- sults reinforce the hypothesis of co-regulation between membrane mitochondrial PPX and mitochondrial hexokinase, and confirm the involvement of reactive oxygen species generation in mitochondria by poly P.

Based on Fig. 3 and Fig. 4, we investigated the hypothesis that polyphosphate (poly $\mathrm{P}_{3}$ and poly $\mathrm{P}_{15}$ ) would also affect scavenger antioxidant enzymes.

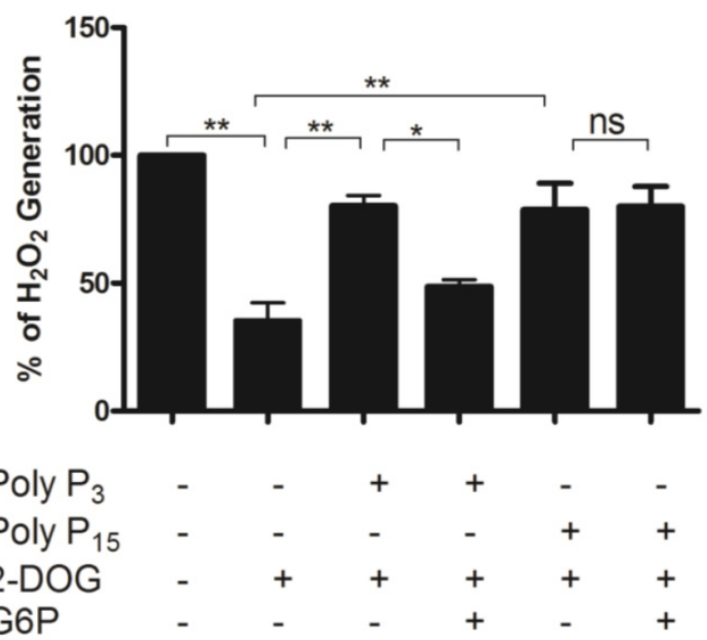

Fig 4. Hydrogen peroxide generation in mitochondria. $\mathrm{H}_{2} \mathrm{O}_{2}$ generation was measured in egg mitochondria $(0.2 \mathrm{mg}$ protein $/ \mathrm{mL})$ on the $9^{\text {th }}$ day of development after addition of $10 \mathrm{mM}$ succinate and I mM ATP with or without $10 \mu \mathrm{M}$ Poly $\mathrm{P}_{3}, 10 \mu \mathrm{M}$ Poly $\mathrm{P}_{15}, 10 \mathrm{mM}$ 2-DOG or $2 \mathrm{mM}$ G6P. Data are the mean \pm S.E. of three independent experiments, in triplicate. ${ }^{*}<<0.05 ;{ }^{*} \mathrm{p}<0.001$.

\section{Regulation of scavenger antioxidant enzymes by inorganic polyphosphate in mitochondria}

We determined the specific activities of scavenger antioxidant enzymes in mitochondrial preparations from eggs during $R$. microplus embryogenesis. The Mn-SOD, CAT and GR activities were higher during embryo cellularization ( $3^{\text {rd }}$ day of development), at the end of embryogenesis (15th day of development) and during embryo segmentation ( $7^{\text {th }}$ day of development), respectively (Figure 5A, 5B and 5C). The profile was not altered after normalizing for mitochondrial recovery using the specific activity of $\mathrm{F}_{1} \mathrm{~F}_{\mathrm{o}}$ APTase as a specific mitochondrial marker instead of mitochondrial protein (data not shown). These results reveal that, during embryogenesis, at least one scavenger antioxidant enzyme shows high levels of activity.

In fact, the rapid developmental kinetics observed in embryogenesis probably requires a readily available energetic support. Our group showed an increase in oxygen consumption as well as rapid sugar mobilization and lipid reservation until the $12^{\text {th }}$ day of development, a period that includes most cell proliferation and reorganization events [54]. As the 
energy demand is high during these steps, pathways involved in energy transduction are increased, thus explaining the high oxygen consumption. However, a transient imbalance in energy demand may lead to an oxidative burst, releasing huge amounts of ROS. Our results are in line with these observations, as Mn-SOD, CAT and GR activities in the mitochondrial fraction were activated during cellularization and embryo segmentation (Figure 5), while only CAT activity remained high after this phase of development. Some of these mechanisms against ROS have previously been characterized in arthropods[48, 60-64]. Antioxidant activity increases in the ovaries in order to protect the Rhodnius prolixus embryo [62]. In R. microplus, mitochondrial CAT activity was higher close to larval eclosion (Figure 5C) and in D. melanogaster it was observed that decreased CAT expression made the eggs fragile, so the embryos died immediately after eclosion [65].

To further investigate if scavenger antioxidant enzymes are regulated by poly $\mathrm{P}$, the influence of different concentrations of poly $\mathrm{P}_{3}$ and $\mathrm{P}_{15}$ on Mn-SOD, CAT and GR were analyzed in mitochondrial fractions. All of the enzymes were stimulated by poly $\mathrm{P}_{3}$. Increasing concentrations of poly $\mathrm{P}_{3}$ increased Mn-SOD, CAT and GR activities by a factor of 10, 3 and 3 , respectively (Figure 6A, 6B and 6C). However, the effect was different using poly $\mathrm{P}_{15}$. Mn-SOD activity, which was the most stimulated by poly $\mathrm{P}_{3}$, was not affected by poly $\mathrm{P}_{15}$, CAT activity was stimulated only by $20 \mu \mathrm{M}$ Poly $\mathrm{P}_{15}$ and GR was the only enzyme that was stimulated in the same way by both poly Ps (Figure 7A, 7B and 7C). These results suggest that regulation by poly $\mathrm{P}$ is dependent on the chain length, and SOD, CAT and GR have different sensitivities to this. As can be seen from Figures $1 B$ and $1 C$, in the presence of mainly poly $\mathrm{P}_{3}$, hexokinase activity was inhibited and Mn-SOD, CAT and GR activities were increased, suggesting a compensatory mechanism of regulation between mitochondrial hexokinase and scavenger antioxidant enzymes by poly $\mathrm{P}$.
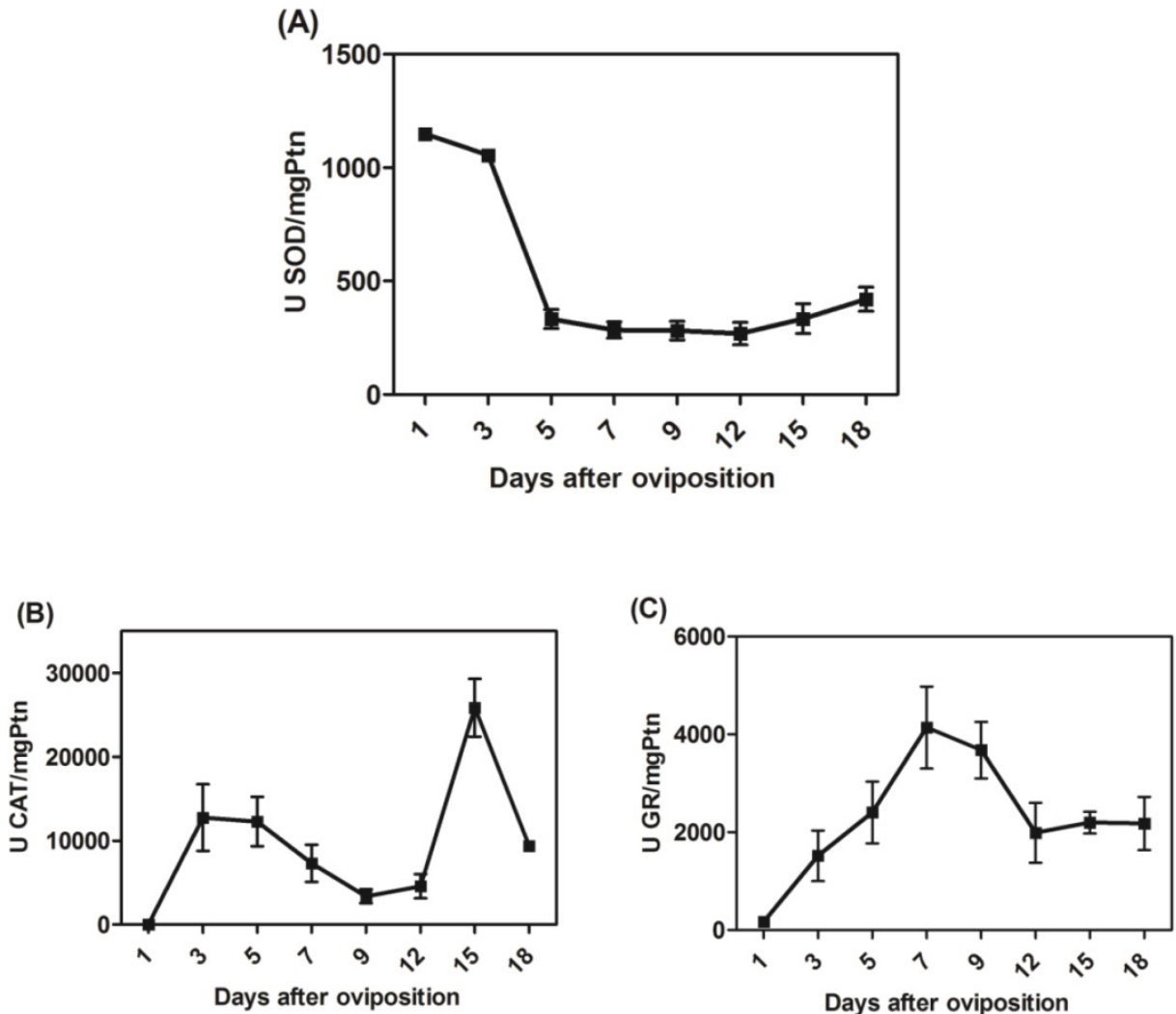

Fig 5. The activities of mitochondrial scavenger antioxidant enzymes. (A) SOD-specific activity was measured in mitochondria on different days after oviposition and is represented as units per milligram of mitochondrial protein. (B) CAT-specific activity was measured in mitochondria on different days after oviposition and is represented as units per milligram of mitochondrial protein. (C) GR-specific activity was measured in mitochondria on different days after oviposition and is represented as units per milligram of mitochondrial protein. All enzyme activities were normalized for mitochondrial recovery using the specific activity of $F_{1} F_{\circ}$ ATPase as a mitochondrial marker instead of mitochondrial protein; the same activity profiles were obtained in both instances (data not shown). 

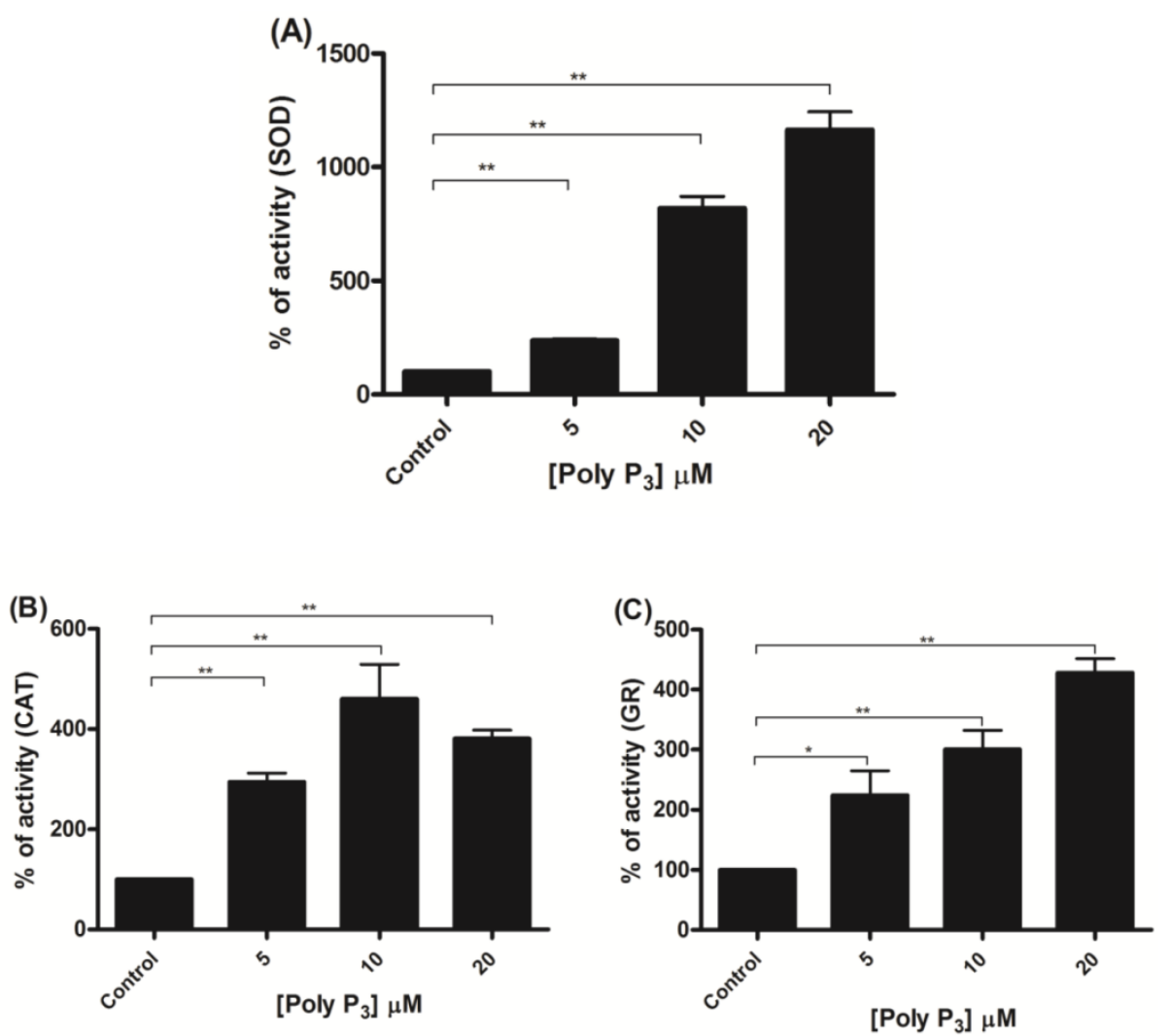

Fig 6. Regulation of scavenger antioxidant enzymes by poly $\mathbf{P}_{3}$. (A) Egg mitochondria on the $3^{\text {rd }}$ day of embryogenesis were isolated and SOD activity was determined in the presence of 5,10 and $20 \mu \mathrm{M}$ poly $\mathrm{P}_{3}$. (B) Egg mitochondria on the $15^{\text {th }}$ day of embryogenesis were isolated and CAT activity was determined in the presence of 5,10 and $20 \mu \mathrm{M}$ poly $\mathrm{P}_{3}$. (C) Egg mitochondria on the $7^{\text {th }}$ day of embryogenesis were isolated and GR activity was determined in the presence of 5,10 and $20 \mu \mathrm{M}$ poly $\mathrm{P}_{3}$. Data are the mean \pm S.E. of three independent experiments, in triplicate. ${ }^{*} \mathrm{p}<0.05 ; * * p<0.001$.
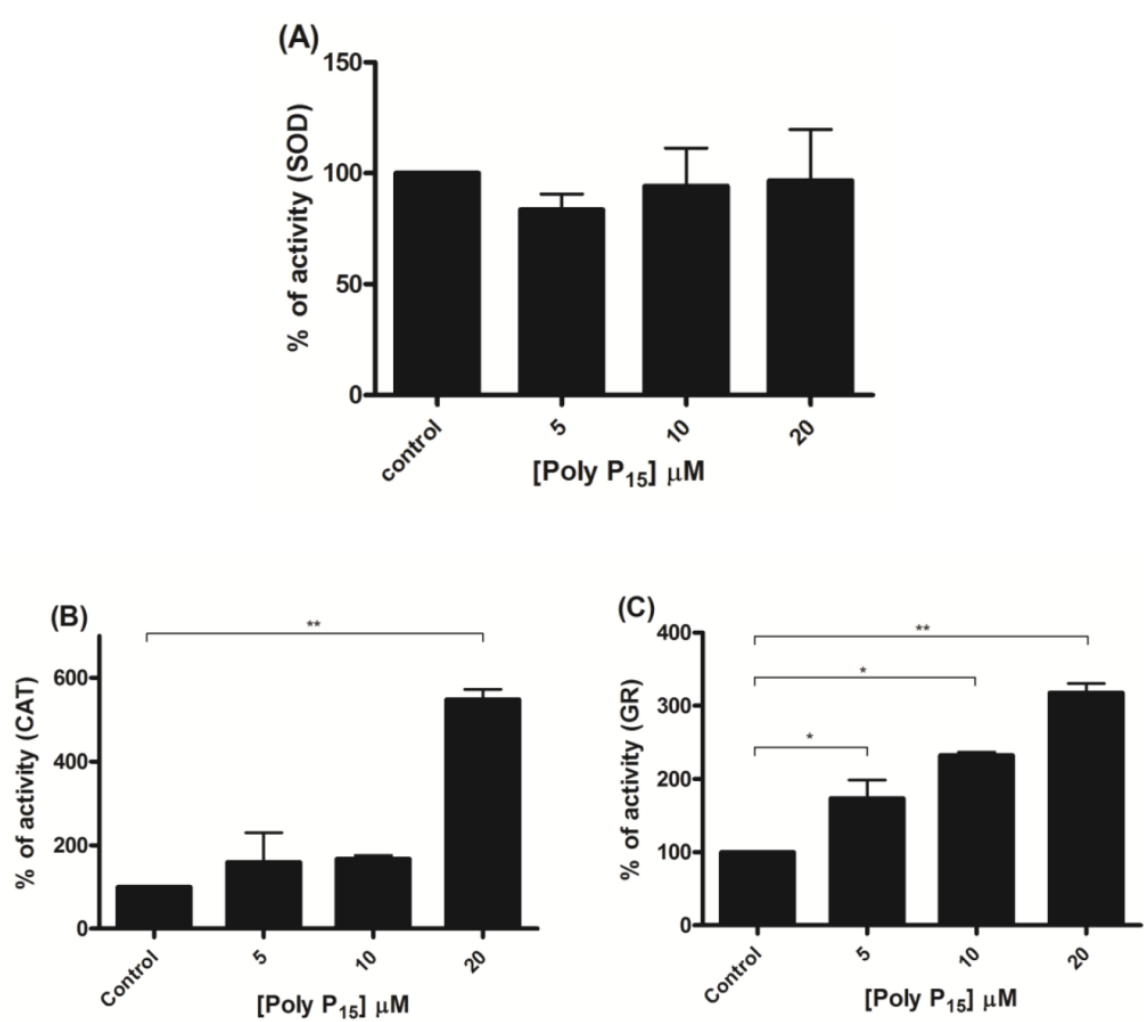

Fig 7. Regulation of scavenger antioxidant enzymes by poly $\mathbf{P}_{15}$. (A) Egg mitochondria on the $3^{\text {rd }}$ day of embryogenesis were isolated and SOD activity was determined in the presence of 5,10 and $20 \mu \mathrm{M}$ poly $P_{15}$. (B) Egg mitochondria on the $15^{\text {th }}$ day of embryogenesis were isolated and CAT activity was determined in the presence of 5,10 and $20 \mu \mathrm{M}$ poly $\mathrm{P}_{15}$. (C) Egg mitochondria on the $7^{\text {th }}$ day of embryogenesis were isolated and GR activity was determined in the presence of 5,10 and $20 \mu \mathrm{M}$ poly $\mathrm{P}_{15}$. Data are the mean $\pm S$.E. of three independent experiments, in triplicate. ${ }^{*} \mathrm{p}<0.05$; ${ }^{* *} \mathrm{p}<0.00 \mathrm{I}$. 


\section{Conclusions}

The schematic diagram in figure 8 summarizes the major findings reported in this work. First, poly $\mathrm{P}$ inhibited mitochondrial hexokinase activity, a situation that increases ROS generation, which is inversely related to the availability of ADP used to drive ATP synthesis. In addition, in a compensatory way, poly $\mathrm{P}$ increases the activities of scavenger antioxidant enzymes, providing compelling evidence that poly $\mathrm{P}$ plays a role in mitochondrial ROS metabolism during $R$. microplus embryogenesis.
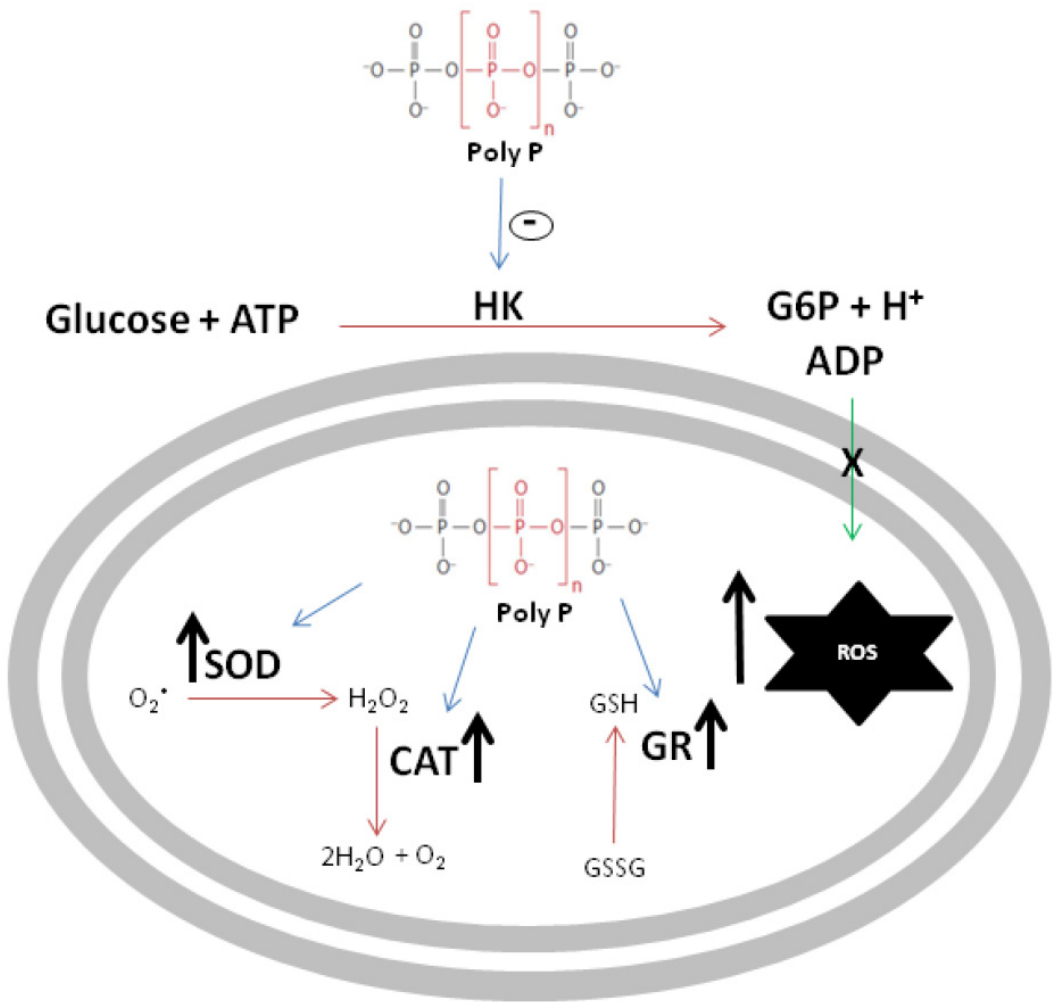

Figure 8. Schematic representation of polyphosphate involvement in reactive oxygen species generation. Black arrows indicate an increase in enzymatic activity or ROS generation, blue arrows indicate poly P modulation of enzymes and green arrow indicates ADP recycling promoted by HK. Poly P represents polyphosphate, HK is mitochondrial hexokinase, ROS denotes reactive oxygen species, SOD is superoxide dismutase, CAT represents catalase and GR denotes glutathione reductase.

\section{Acknowledgments}

Research at Laboratório de Bioquímica Hatisaburo Masuda/NUPEM-UFRJ-Macaé (LIBHM) and at Laboratório Química e Função de Proteínas e Peptídeos, Universidade Estadual Norte Fluminense, Campos dos Goytacazes, RJ, Brazil is funded by FAPERJ, FUNEMAC, CAPES, CNPq and INCT-Entomologia Molecular. Amanda Fraga is a master student from PPG-PRODBIO-UFRJ-Macaé. We would like to thank Simone Gomes for technical assistance. Tick adults were a kind gift of Emerson Pontes and Itabajara Vaz. We dedicate this paper to the memory of Alexandre A. Peixoto.

\section{Conflict of Interest}

The authors declare no conflict of interest.

\section{Competing Interests}

The authors have declared that no competing interest exists.

\section{References}

1. Kornberg A, Rao NN, Ault-Riche D. Inorganic polyphosphate: A molecule of many functions. Annu Rev Biochem. 1999; 68: 89-125. doi: 10.1146/annurev.biochem.68.1.89.

2. Kulaev I, Kulakovskaya T. Polyphosphate and phosphate pump. Annu Rev Microbiol. 2000; 54: 709-34. doi: 10.1146/annurev.micro.54.1.709.

3. Jones HE, Holland IB, Jacq A, Wall T, Campbell AK. Escherichia coli lacking the AcrAB multidrug efflux pump also lacks nonproteinaceous, PHB-polyphosphate $\mathrm{Ca} 2+$ channels in the membrane. Bba-Biomembranes. 2003; 1612 : 90-7. 10.1016/S0005-2736(03)00082-8.

4. Reusch RN. Poly-Beta-Hydroxybutyrate Calcium Polyphosphate Complexes in Eukaryotic Membranes. P Soc Exp Biol Med. 1989; 191: 377-81.

5. Kim KS, Rao NN, Fraley CD, Kornberg A. Inorganic polyphosphate is essential for long-term survival and virulence factors in Shigella and Salmonella spp. P Natl Acad Sci USA. 2002; 99: 7675-80. doi: $10.1073 /$ pnas.112210499. 
6. Rashid $\mathrm{MH}$, Rumbaugh $\mathrm{K}$, Passador L, Davies DG, Hamood AN, Iglewski $\mathrm{BH}$, et al. Polyphosphate kinase is essential for biofilm development, quorum sensing, and virulence of Pseudomonas aeruginosa. P Natl Acad Sci USA. 2000; 97: 9636-41. doi: $10.1073 /$ pnas.170283397.

7. McInerney P, Mizutani T, Shiba T. Inorganic polyphosphate interacts with ribosomes and promotes translation fidelity in vitro and in vivo. Mol Microbiol. 2006; 60: 438-47. doi: 10.1111/j.1365-2958.2006.05103.x.

8. Kuroda A, Nomura K, Ohtomo R, Kato J, Ikeda T, Takiguchi N, et al. Role of inorganic polyphosphate in promoting ribosomal protein degradation by the Lon protease in E. coli. Science. 2001; 293: 705-8. doi:10.1126/science.1061315.

9. Wang L, Fraley CD, Faridi J, Kornberg A, Roth RA. Inorganic polyphosphate stimulates mammalian TOR, a kinase involved in the proliferation of mammary cancer cells. Proc Natl Acad Sci U S A. 2003; 100: 11249-54. doi:10.1073/pnas.1534805100.

10. Smith SA, Mutch NJ, Baskar D, Rohloff P, Docampo R, Morrissey JH. Polyphosphate modulates blood coagulation and fibrinolysis. Proc Natl Acad Sci U S A. 2006; 103: 903-8. doi:10.1073/pnas.0507195103.

11. Hernandez-Ruiz L, Gonzalez-Garcia I, Castro C, Brieva JA, Ruiz FA. Inorganic polyphosphate and specific induction of apoptosis in human plasma cells. Haematol-Hematol J. 2006; 91: 1180-6.

12. Kawano MM. Inorganic polyphosphate induces apoptosis specifically in human plasma cells. Haematologica. 2006; 91: 1154A.

13. Lorenz B, Munkner J, Oliveira MP, Kuusksalu A, Leitao JM, Muller WEG, et al. Changes in metabolism of inorganic polyphosphate in rat tissues and human cells during development and apoptosis. Bba-Gen Subjects. 1997; 1335: 51-60. doi: 10.1016/S0304-4165(96)00121-3.

14. Pavlov E, Aschar-Sobbi R, Campanella M, Turner RJ, Gomez-Garcia MR, Abramov AY. Inorganic Polyphosphate and Energy Metabolism in Mammalian Cells. J Biol Chem. 2010; 285: 9420-8. doi: 10.1074/jbc.M109.013011.

15. Abramov AY, Fraley C, Diao CT, Winkfein R, Colicos MA, Duchen MR, et al. Targeted polyphosphatase expression alters mitochondrial metabolism and inhibits calcium-dependent cell death. P Natl Acad Sci USA. 2007; 104: 18091-6. doi: 10.1073/pnas.0708959104.

16. Clements A, Bursac D, Gatsos X, Perry AJ, Civciristov S, Celik N, et al. The reducible complexity of a mitochondrial molecular machine. P Natl Acad Sci USA. 2009; 106: 15791-5. doi: 10.1073/pnas.0908264106.

17. Kulakovskaya TV, Lichko LP, Vagabov VM, Kulaev IS. Inorganic Polyphosphates in Mitochondria. Biochemistry-Moscow + . 2010; 75: 825-31. doi: 10.1134/S0006297910070035.

18. Campos E, Facanha AR, Costa EP, Fraga A, Moraes J, Vaz ID, et al. A Mitochondrial Membrane Exopolyphosphatase Is Modulated by, and Plays a Role in, the Energy Metabolism of Hard Tick Rhipicephalus (Boophilus) microplus Embryos. Int J Mol Sci. 2011; 12: 3525-35. doi: 10.3390/Ijms12063525.

19. Cardenas ML, Cornish-Bowden A, Ureta T. Evolution and regulatory role of the hexokinases. Biochimica et biophysica acta. 1998; 1401: 242-64.

20. Ford WC, Candy DJ. The regulation of glycolysis in perfused locust flight muscle. The Biochemical journal. 1972; 130: 1101-12.

21. Fritz HL, Smoak IW, Branch S. Hexokinase I expression and activity in embryonic mouse heart during early and late organogenesis. Histochemistry and cell biology. 1999; 112: 359-65.

22. Frommer WB, Schulze WX, Lalonde S. Plant science. Hexokinase, Jack-of-all-trades. Science. 2003; 300: 261-3. doi:10.1126/science.1084120.

23. Gonzalez-Alvarez R, Ortega-Cuellar D, Hernandez-Mendoza A, Moreno-Arriola E, Villasenor-Mendoza K, Galvez-Mariscal A, et al. The hexokinase gene family in the zebrafish: Structure, expression, functional and phylogenetic analysis. Comp Biochem Phys B. 2009; 152: 189-95. doi: 10.1016/j.cbpb.2008.11.004.

24. Fraga A, Ribeiro L, Lobato M, Santos V, Silva JR, Rezende G, et al. Glycogen and Glucose metabolism are essential for early embryonic development of the red flour beetle Tribolium castaneum. PloS One. 2013

25. Bork P, Sander C, Valencia A. Convergent Evolution of Similar Enzymatic Function on Different Protein Folds - the Hexokinase, Ribokinase, and Galactokinase Families of Sugar Kinases. Protein Sci. 1993; 2: 31-40.

26. Wilson JE. Isozymes of mammalian hexokinase: structure, subcellular localization and metabolic function. J Exp Biol. 2003; 206: 2049-57. doi: 10.1242/Jeb.00241.

27. Santiago APSA, Chaves EA, Oliveira MF, Galina A. Reactive oxygen species generation is modulated by mitochondrial kinases: Correlation with mitochondrial antioxidant peroxidases in rat tissues. Biochimie. 2008; 90: 1566-77. doi: 10.1016/j.biochi.2008.06.013.

28. Gardner PR, Raineri I, Epstein LB, White CW. Superoxide Radical and Iron Modulate Aconitase Activity in Mammalian-Cells. J Biol Chem. 1995; 270: 13399-405.
29. Okado-Matsumoto A, Fridovich I. Subcellular distribution of superoxide dismutases (SOD) in rat liver: $\mathrm{Cu}, \mathrm{Zn}-\mathrm{SOD}$ in mitochondria. J Biol Chem. 2001; 276: 38388-93. doi:10.1074/jbc.M105395200.

30. Sturtz LA, Diekert K, Jensen LT, Lill R, Culotta VC. A fraction of yeast $\mathrm{Cu}, \mathrm{Zn}$-superoxide dismutase and its metallochaperone, CCS, localize to the intermembrane space of mitochondria. A physiological role for SOD1 in guarding against mitochondrial oxidative damage. J Biol Chem. 2001; 276: 38084-9. doi:10.1074/jbc.M105296200.

31. Weisiger RA, Fridovic I. Superoxide Dismutase - Organelle Specificity. J Biol Chem. 1973; 248: 3582-92.

32. Weisiger RA, Fridovich I. Mitochondrial superoxide simutase. Site of synthesis and intramitochondrial localization. J Biol Chem. 1973; 248: 4793-6.

33. Kowaltowski AJ, de Souza-Pinto NC, Castilho RF, Vercesi AE. Mitochondria and reactive oxygen species. Free radical biology \& medicine. 2009; 47: 333-43. doi:10.1016/j.freeradbiomed.2009.05.004.

34. Salvi M, Battaglia V, Brunati AM, La Rocca N, Tibaldi E, Pietrangeli P, et al. Catalase takes part in rat liver mitochondria oxidative stress defense. J Biol Chem. 2007; 282: 24407-15. doi:10.1074/jbc.M701589200.

35. Schriner SE, Linford NJ, Martin GM, Treuting P, Ogburn CE, Emond M, et al. Extension of murine life span by overexpression of catalase targeted to mitochondria. Science. 2005; 308: 1909-11. doi:10.1126/science.1106653.

36. Dringen R. Metabolism and functions of glutathione in brain. Progress in neurobiology. 2000; 62: 649-71.

37. Sonenshine DE, Kocan KM, de la Fuente J. Tick control: further thoughts on a research agenda. Trends Parasitol. 2006; 22: 550-1. doi: 10.1016/J.Pt.2006.09.003.

38. Guerrero FD, Nene VM, George JE, Barker SC, Willadsen P. Sequencing a new target genome: the Boophilus microplus (Acari: Ixodidae) genome project. Journal of medical entomology. 2006; 43: 9-16.

39. Parizi LF, Pohl PC, Masuda A, Vaz ID. New approaches toward anti-Rhipicephalus (Boophilus) microplus tick vaccine. Rev Bras Parasitol V. 2009; 18: 1-7.

40. Fagotto F. Yolk Degradation in Tick Eggs. 1. Occurrence of a Cathepsin L-Like Acid Proteinase in Yolk Spheres. Arch Insect Biochem. 1990; 14: 217-35. doi: 10.1002/arch.940140403.

41. Logullo C, Moraes J, Dansa-Petretski M, Vaz IS, Masuda A, Sorgine $\mathrm{MHF}$, et al. Binding and storage of heme by vitellin from the cattle tick, Boophilus microplus. Insect Biochem Molec. 2002; 32: 1805-11. doi:Pii S0965-1748(02)00162-5. Doi 10.1016/S0965-1748(02)00162-5.

42. Campos E, Facanha A, Moraes J, et al. A mitochondrial exopolyphosphatase activity modulated by phosphate demand in Rhipicephalus (Boophilus) microplus embryo. Insect Biochem Mol Biol. 2007; 37: 1103-7. doi:10.1016/j.ibmb.2007.06.003.

43. Lowry OH, Rosebrough NJ, Farr AL, Randall RJ. Protein measurement with the Folin phenol reagent. J Biol Chem. 1951; 193: 265-75.

44. Fiske $\mathrm{CH}$, Subbarow $\mathrm{Y}$. The Nature of the "Inorganic Phosphate" in Voluntary Muscle. Science. 1927; 65: 401-3. doi:10.1126/science.65.1686.401.

45. Votyakova TV, Reynolds IJ. Detection of hydrogen peroxide with Amplex Red: interference by NADH and reduced glutathione auto-oxidation. Archives of biochemistry and biophysics. 2004; 431: 138-44. doi:10.1016/j.abb.2004.07.025.

46. Beauchamp C, Fridovich I. Superoxide dismutase: improved assays and an assay applicable to acrylamide gels. Analytical biochemistry. 1971; 44: 276-87.

47. Aebi H. Catalase in vitro. Methods in enzymology. 1984; 105: 121-6.

48. Freitas DRJ, Rosa RM, Moraes J, Campos E, Logullo C, Vaz ID, et al. Relationship between glutathione S-transferase, catalase, oxygen consumption, lipid peroxidation and oxidative stress in eggs and larvae of Boophilus microplus (Acarina : Ixodidae). Comp Biochem Phys A. 2007; 146: 688-94. doi: 10.1016/j.cbpa.2006.04.032.

49. Mizuno Y. Changes in superoxide dismutase, catalase, glutathione peroxidase, and glutathione reductase activities and thiobarbituric acid-reactive products levels in early stages of development in dystrophic chickens. Experimental neurology. 1984; 84: 58-73.

50. Gabel NW, Thomas V. Evidence for the occurrence and distribution of inorganic polyphosphates in vertebrate tissues. Journal of neurochemistry. 1971; 18: 1229-42.

51. Campos E, Facanha AR, Costa EP, da Silva Vaz I, Jr., Masuda A, Logullo C. Exopolyphosphatases in nuclear and mitochondrial fractions during embryogenesis of the hard tick Rhipicephalus (Boophilus) microplus. Comparative biochemistry and physiology Part B, Biochemistry \& molecular biology. 2008; 151: 311-6. doi:10.1016/j.cbpb.2008.07.013.

52. Gomes FM, Oliveira DM, Motta LS, Ramos IB, Miranda KM, Machado EA. Inorganic polyphosphate inhibits an aspartic protease-like activity in the eggs of Rhodnius prolixus (Stahl) and impairs yolk mobilization in 
vitro. Journal of cellular physiology. 2010; 222: 606-11. doi:10.1002/jcp.21975.

53. Monnerat AT, Machado MP, Vale BS, Soares MJ, Lima JBP, Lenzi HL, et al. Anopheles albitarsis embryogenesis: Morphological identification of major events. Mem I Oswaldo Cruz. 2002; 97: 589-96.

54. Campos E, Moraes J, Facanha AR, Moreira E, Valle D, Abreu L, et al. Kinetics of energy source utilization in Boophilus microplus (Canestrini, 1887) (Acari : Ixodidae) embryonic development. Vet Parasitol. 2006; 138: 349-57. doi: 10.1016/j.vetpar.2006.02.004.

55. Moraes J, Galina A, Alvarenga PH, Rezende GL, Masuda A, Vaz ID, et al. Glucose metabolism during embryogenesis of the hard tick Boophilus microplus. Comp Biochem Phys A. 2007; 146: 528-33. doi: 10.1016/j.cbpa.2006.05.009.

56. da-Silva WS, Gomez-Puyou A, de Gomez-Puyou MT, Moreno-Sanchez R, De Felice FG, de Meis L, et al. Mitochondrial bound hexokinase activity as a preventive antioxidant Defense - Steady-state ADP formation as a regulatory mechanism of membrane potential and reactive oxygen species generation in mitochondria. J Biol Chem. 2004; 279: 39846-55. doi: 10.1074/jbc.M403835200.

57. Korshunov SS, Skulachev VP, Starkov AA. High protonic potential actuates a mechanism of production of reactive oxygen species in mitochondria. Febs Lett. 1997; 416: 15-8. doi: 10.1016/S0014-5793(97)01159-9.

58. Wei Z, Ibrahim W, StClair DK, Chow CK. Increased mitochondrial generation of hydrogen peroxide in the skeletal muscle and liver of vitamin E-deficient mice. Faseb J. 1997; 11: 3380.

59. Meyer LE, Machado LB, Santiago AP, da-Silva WS, De Felice FG, Holub $\mathrm{O}$, et al. Mitochondrial creatine kinase activity prevents reactive oxygen species generation: antioxidant role of mitochondrial kinase-dependent ADP re-cycling activity. J Biol Chem. 2006; 281: 37361-71. doi:10.1074/jbc.M604123200.

60. Andrews ES, Crain PR, Fu Y, Howe DK, Dobson SL. Reactive oxygen species production and Brugia pahangi survivorship in Aedes polynesiensis with artificial Wolbachia infection types. PLoS pathogens. 2012; 8: e1003075. doi:10.1371/journal.ppat.1003075.

61. Diaz-Albiter H, Sant'Anna MR, Genta FA, Dillon RJ. Reactive oxygen species-mediated immunity against Leishmania mexicana and Serratia marcescens in the sand phlebotomine fly Lutzomyia longipalpis. J Biol Chem. 2012; 287: 23995-4003. doi:10.1074/jbc.M112.376095.

62. Paes MC, Oliveira MB, Oliveira PL. Hydrogen peroxide detoxification in the midgut of the blood-sucking insect, Rhodnius prolixus. Arch Insect Biochem Physiol. 2001; 48: 63-71. doi:10.1002/arch.1058.

63. Pan X, Zhou G, Wu J, Bian G, Lu P, Raikhel AS, et al. Wolbachia induces reactive oxygen species (ROS)-dependent activation of the Toll pathway to control dengue virus in the mosquito Aedes aegypti. Proc Natl Acad Sci U S A. 2012; 109: E23-31. doi:10.1073/pnas.1116932108.

64. Park SY, Nair PM, Choi J. Characterization and expression of superoxide dismutase genes in Chironomus riparius (Diptera, Chironomidae) larvae as a potential biomarker of ecotoxicity. Comparative biochemistry and physiology Toxicology \& pharmacology : CBP. 2012; 156: 187-94. doi:10.1016/j.cbpc.2012.06.003.

65. Poirier L, Seroude L. Genetic approaches to study aging in Drosophila melanogaster. Age. 2005; 27: 165-82. doi: 10.1007/s11357-005-2919-9. 